2017-02-01

\title{
Sudden unexpected death in epilepsy: measures to reduce risk
}

Mclean, B

http://hdl.handle.net/10026.1/11648

10.1136/practneurol-2016-001392

Practical Neurology

BMJ

All content in PEARL is protected by copyright law. Author manuscripts are made available in accordance with publisher policies. Please cite only the published version using the details provided on the item record or document. In the absence of an open licence (e.g. Creative Commons), permissions for further reuse of content should be sought from the publisher or author. 


\title{
Sudden unexpected death in epilepsy: measures to reduce risk
}

\author{
Brendan Mclean, ${ }^{1}$ Rohit Shankar, ${ }^{2,3}$ Jane Hanna, ${ }^{4}$ Caryn Jory, ${ }^{2}$ \\ Craig Newman ${ }^{5}$
}

${ }^{1}$ Neurology Department, Royal Cornwall Hospitals NHS Trust, Truro, , UK

${ }^{2}$ Cornwall Partnership NHS Foundation Trust, Truro, UK ${ }^{3}$ Exeter Medical School Truro, Exeter, UK

${ }^{4}$ SUDEP Action, Wantage, UK ${ }^{5}$ Department of

Neuropsychology, Plymouth University, Plymouth, Devon, UK

\section{Correspondence to}

Dr Brendan Mclean, Neurology Department, Royal Cornwall Hospitals NHS Trust, Treliske, Truro TR1 3L, UK; brendan. mclean@nhs.net

Accepted 2 November 2016

To cite: Mclean $B$, Shankar R, Hanna J, et al. Pract Neurol Published Online First: [please include Day Month Year] doi:10.1136/ practneurol-2016-001392

\begin{abstract}
This review looks at the strategies that may help to reduce the risk of sudden unexpected death in epilepsy beyond that of trying to achieve seizure cessation, which is not possible for up to $30 \%$ of patients with epilepsy. These strategies include seizure safety checklists, mobile phone technology, telehealth and various devices currently available or in development. We highlight interventions where there is evidence of benefit, and draw attention for the need both to involve patients with epilepsy in risk reduction and to improve communication with those at risk.
\end{abstract}

\section{INTRODUCTION}

There is nothing so tragic as a life needlessly lost.

The consequences of epilepsy are manifold. Aside from the effects it has on peoples' lives as a result of social consequences (employment, driving, schooling and sporting) and medication (side effects, contraception and pregnancy), there are medical consequences with the risk of injuries, cognitive problems and ultimately premature death. Epilepsy is the fifth highest cause of life years lost, second only to stroke as a neurological disorder, and the most common cause of death in younger people. ${ }^{1-3}$

The National Sentinel Audit of epilepsy-related deaths in 2002 recorded 1200 epilepsy-related deaths annually in the UK, of which $42 \%$ were felt to be avoidable. ${ }^{1}$ In 2013 there were 1187 deaths attributed to epilepsy in England and Wales, suggesting little progress in attempting to reduce the risk. ${ }^{4}$ Sudden unexpected death in epilepsy (SUDEP), defined as death not due to accidents or witnessed seizures, peaks in young adults; about $1 \%$ of young men with epilepsy die before the age of 30 years. ${ }^{5}$

Strategies to reduce the risk of SUDEP must involve not only people with epilepsy but also their general practitioners. General practitioners have the most medical contact with people with epilepsy, not just for their epilepsy but also for other conditions that may also influence risk, such as depression and substance misuse. ${ }^{6} 7$ The UK's National Institute for Health and Care Excellence epilepsy guidelines from 2004 to 2012 clearly state that the risk of death in epilepsy, in particular SUDEP, should be discussed as a priority at the time of diagnosis. $^{8} 9$ Its equivalent in Scotland, the Scottish Intercollegiate Guidelines Network epilepsy guidelines 2015, suggests discussion about SUDEP at an 'appropriate time'. ${ }^{10}$ Despite this risk, there is a tacit avoidance of discussing the risk of death both in primary and secondary care, while the patient organisations and SUDEP Action (formerly Epilepsy Bereaved) vociferously support the patients' view that such risks should be made transparent (see box 1). This article sets out strategies that may help clinicians to improve person-centred communication when dealing with epilepsy, to reduce this risk. ${ }^{11}$

\section{INITIAL MEASURES TO REDUCE RISK}

Reducing seizure frequency, particularly tonic-clonic seizures, may seem selfevident as a primary goal, but until a recent meta-analysis of randomised controlled trials there was little evidence that reducing seizures did reduce SUDEP risk. ${ }^{12}$ Achieving this requires a cohesive approach from clinicians and teams with expertise in epilepsy. For that reason, a diagnosis of epilepsy should only be made by someone with an interest in epilepsy, be that a general neurologist or an epileptologist. The initial management should use a team approach, with the epilepsy nurse specialist (if available) being central. Information provided sensitively 


\section{Box 1 Quote from a patient-with permission}

The patient who has epilepsy commented: "EpSMon is just what I need to monitor my risk in between visits to doctors. It helps me take actions at all times as it measures my own particular risks of epilepsy. It can act as a safety net, being an excellent reminder of the importance of taking medication correctly and seeing my GP on a regular basis."

at an early stage empowers people with epilepsy, and we propose an early discussion about SUDEP, usually at the first follow-up after confirmation of diagnosis, as raising this issue at the diagnostic stage can be too difficult for some. In our practice, most people with epilepsy (and their families or carers) welcome the discussion of SUDEP, and find that this helps the discussion around many aspects of management. ${ }^{13}$

The choice of antiepileptic medication is important, as some may worsen certain epilepsies (eg, carbamazepine and myoclonic epilepsies). While up to $70 \%$ of patients become seizure free on their first choice for monotherapy, it is important to pay heed to reported side effects, not least because of the risk of nonconcordance. Thirty per cent of people with longterm conditions in general do not take their medications regularly; epilepsy is no exception. ${ }^{14}$

Women in their fertile years require special consideration, and antiepileptic drug interactions with hormonal contraception, fears about teratogenicity, vomiting in pregnancy and blood concentration changes all demand a proactive approach. Specific clinics particularly linked to maternity services may help. ${ }^{15}$

Choosing an easy dosing regimen also helps-once daily dosing may suit some patients-and always enquire about the ease of swallow and palatability of medicines, since problems with these may reduce concordance. In people with intellectual disability and percutaneous endoscopic gastrostomy feeding, there may be formulation issues that influence absorption.

When first-line treatments fail, leaving the patient with refractory epilepsy, the clinician should consider planned sequential monotherapy or polytherapy. In one study, up to $16 \%$ of people whose epilepsy was considered refractory became seizure free or significantly improved. ${ }^{16}$ People with epilepsy often respond positively to participation in clinical trials, audits and studies, and centres participating in such activities report greater patient satisfaction and better outcomes.

It is worth considering surgical interventions when medical management fails. Resective surgery remains the gold standard for selected people with epilepsy, with reported seizure freedom rates of $70 \%$ for temporal and 50\% for extra-temporal procedures, although long-term data show that seizures may recur. ${ }^{17}$ Vagus nerve stimulation is often considered when resective surgery is not appropriate for various reasons, such as an unclear seizure focus, comorbidities, possible cognitive risks and so on. Many people with epilepsy prefer this option, and recent advances in device technologies now provide automated triggering, based on the heart rate changes that may accompany seizure onset. ${ }^{18}$

\section{DISCUSSING SUDEP}

Discussing SUDEP has been controversial and some countries still advocate a paternalistic approach on a 'need to know basis.' ${ }^{19}$ A recent court judgement in Scotland supported the view that people with epilepsy and their families were entitled to be provided with such information at an early stage (see box 2 for website links). The timing of such a discussion should be tailored to individual needs. Sometimes an early discussion is not appropriate; for example, if there is active psychiatric comorbidity or epilepsy has occurred in the setting of a malignant cerebral tumour. In patients with intellectual disability, the family and carers usually wish to know as early as possible. In our practice, we have this discussion using a structured approach and aided by the SUDEP and seizure safety checklist (box 1) at diagnosis in people with intellectual disability, and at the first follow-up in those without.

\section{SUDEP RISK CHECKLIST}

\section{The SUDEP and seizure safety checklist}

Common sense suggests anything that reduces seizure frequency should reduce mortality; hence improving concordance with medication, avoiding seizure

\section{Box 2 Useful websites}

https://www.sudep.org/checklist—seizure safety checklist https://www.sudep.org//epilepsy-self-monitor-epilepsy self-monitor (EpSMon) https://www.youtube.com/watch?v=e3mECsSVgHIEpsMon demonstration video https://www.youtube.com/watch?v=Z9KHQvsapAcadministering seizure safety checklist

http://www.who.int/patientsafety/safesurgery/checklist/en/ -the surgical safety checklist

http://cdrwww.who.int/patientsafety/safesurgery/

Surgical_Safety_Checklist.pdf_-surgical safety checklist in use

http://qualitysafety.bmj.com/content/early/2014/07/18/ bmjgs-2013-002772.full-patients' views on the surgical safety checklist

http://www.epilepsytoolkit.org.uk/—national epilepsy toolkit

http://www.scotland-judiciary.org.uk/10/794/

Fatal-Accident-Inquiry-into-the-deaths-of-Erin-Casey-andChristina-Fiorre-llia-the Scottish fatal accident enquiry 
triggers and so on are all part of our routine care plans. However, the evidence basis for this commonsense approach derives only from retrospective studies. While there are common themes, there is no consensus on a standardised approach to risk reduction.

Safety checklists now form part of routine clinical practice, particularly in surgery where they reduce morbidity and mortality; both clinicians and patient groups support their use ${ }^{20}$ (see box 1 for website links). Creating such lists requires a detailed assessment and validation of the variables that contribute to risk.

There are numerous studies looking at the risk factors for SUDEP. An in-depth review of the literature identified 18 risk factors, ${ }^{7}{ }^{21}$ leading to our development of a safety checklist (figure 1A, B). Of the 18 factors, 11 were potentially modifiable, particularly non-adherence to antiepileptic medications, substance misuse, mood disorders and sleep disruption (see https://www.sudep.org/checklist to register, see training videos and access a copy). There is no absolute risk assigned to each item, nor to the sum of the items, but completing the list allows a discussion around risk modification. Detailed analysis and stratification of the risk factors show that some are more significant than others. ${ }^{22}$ Despite initial fears that raising the issues might cause unnecessary alarm, patients tend to receive it positively ${ }^{13}$ and using the checklist can modify behaviours. ${ }^{23}$

The charity 'SUDEP Action' launched the SUDEP and seizure safety checklist in the UK in 2015. There are 19 questions covering SUDEP and seizure safety risk, updated from evidence on SUDEP and fatality risk in epilepsy, and a question about the use of emergency services. Administering the checklist takes about $10 \mathrm{~min}$, although discussion around the identified risks takes longer. Partners/carers of people with epilepsy are often more positive than patients about the checklist-after all, they watch the seizures and pick up the pieces afterwards.

While a clinic-led safety checklist is a step forward, it requires the patient to attend; hence we need an empowerment tool in the community. Lack of engagement with services is an identified risk. In $90 \%$ of SUDEP cases, there was deteriorating seizure control in the 3-6 months before death, and most had not had an epilepsy review for at least a year. ${ }^{24}$ Thus, while simple strategies can reduce or better manage risk, these interventions also need to be positioned either in primary care or with the patients themselves.

\section{TELEHEALTH}

Telehealth projects are well established in other disciplines, such as cardiac failure and chronic obstructive pulmonary disease. Such systems have now been piloted in epilepsy in a primary care setting using a telehealth non-clinical professional to contact people perceived to be at high risk every 3 months. Seventeen per cent of patients had an intervention that would otherwise have not happened. ${ }^{23}$ This programme is potentially cheaper than medically led interventions, seems acceptable to patients and general practitioners, has not resulted in increased referrals to secondary care and is now being developed over a larger primary care population.

\section{MOBILE EHEALTH (SMARTPHONES, etc)}

The use of technology is often overlooked in medicine. The at-risk age group for SUDEP is smartphone savvy, and this seems an obvious aid to communication and risk assessment. There is now a mobile phone app, epilepsy self-monitor (EpSMon) based on the safety checklist (figure 2A, B), available free on iPhone and Android (see box 1 for website links). It is patient driven, and reminds the user to repeat the assessment every 3 months. Risks are summarised and, if present, the app suggests a review with the general practitioner and provides relevant education. Data are stored on a secure server along with a university governance policy for research purposes (made available on application to suitable research groups). The Epilepsy Foundation (USA) is to release the app 'EpSMon USA' shortly, with evidence of its continued usability and model of delivery. ${ }^{25}$ While there has been a flood of medical apps across many conditions in recent years-many unregulated, unevidenced and of doubtful benefits-the involvement of the evidence, users, charities and professionals in app development has led to EpSMon and the SUDEP and seizure safety checklist being recognised as part of the national epilepsy toolkit (see box 1 for website links).

The press and social media showed considerable interest in EpSMon, and the launch of the iOS version for mobile phones featured in The Guardian newspaper (figure 3). This type of publicity can help to reduce the stigma of epilepsy and to spread public awareness of its risks as a lifelong condition. It gives patients a positive message that they can be 'empowered' to take charge of their condition (see box 1).

Nevertheless, a barrier to the use of the apps is the lack of awareness of risks of epilepsy, which the public generally consider as 'safe'. In addition, the 3-month gap between assessments could disengage the user. Such apps clearly need continued advertising and collaboration with patient groups and development of a seizure and medication monitoring daily diary.

Certain other factors such as bias of self-reporting are more difficult to address and felt to be a 'necessary evil' to take advantage of patient selfempowerment. The expectation is that with repeated reviews and research of growing usage data this bias could be reduced over time.

\section{DEVICE TECHNOLOGY}

A recent systemic review into available commercial seizure detection devices showed no suitable robust seizure detection and safety technology though some 


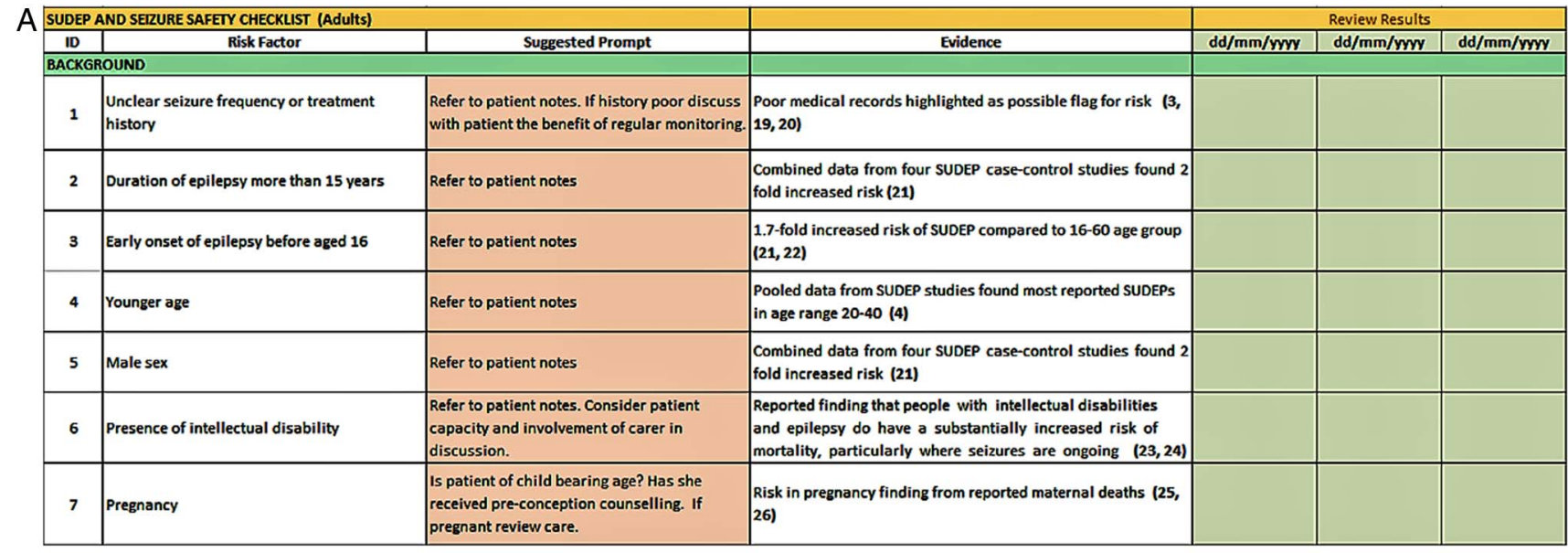

\begin{tabular}{|c|c|c|c|c|c|c|}
\hline \multicolumn{4}{|c|}{ RELATED RISKS } & \multirow[b]{2}{*}{ Yes } & \multirow[b]{2}{*}{ Yes } & \multirow[b]{2}{*}{ No } \\
\hline 12 & Lack of surveillance at night & $\begin{array}{l}\text { What happens if you have a night time } \\
\text { seizure? }\end{array}$ & $\begin{array}{l}\text { Nocturnal supervision found to be protective in SUDEP study } \\
\text { (19) } \\
\text { Lack of supervision frequently noted when SUDEP occurred in } \\
\text { Epilepsy Monitoring Units (29) } \\
\text { SUDEP is frequently unwitnessed (30) }\end{array}$ & & & \\
\hline 13 & Prone position & $\begin{array}{l}\text { No question to patient advised unless } \\
\text { considered appropriate }\end{array}$ & $\begin{array}{l}\text { Systematic review highlights significant association between } \\
\text { SUDEP and prone position (31) }\end{array}$ & Unknown & Unknown & Unknown \\
\hline 14 & Injuries or use of emergency services & $\begin{array}{l}\text { Have you had any injuries or ED/999 } \\
\text { emergency service calls ? }\end{array}$ & Injuries have been identified as a risk factor for mortality (12) & Yes & No & No \\
\hline 15 & Medicines non-adherence issues & $\begin{array}{l}\text { Do you have any difficulties taking your } \\
\text { medication as prescribed? } \\
\text { e.g. } \\
\text { prest times forrestiption; the taste to to the medication is } \\
\text { bad; at times questioning the benefits of the } \\
\text { medication or f feeling that they need more } \\
\text { information or support to take the epilepsy } \\
\text { medication. }\end{array}$ & $\begin{array}{l}\text { Non-adherence with AED associated with a } 3 \text { fold increase in } \\
\text { mortality (33) } \\
\text { Not collecting scripts for } 91 \text {-192 days carried a higher } \\
\text { mortality risk (12) } \\
\text { Patients seizure free with AEDs showed no excess mortality } \\
\text { (32) } \\
\text { AEDs at efficacious doses may reduce SUDEP (34) } \\
\text { AED hair strand levels showed greater variability in SUDEP } \\
\text { cases (35) }\end{array}$ & Yes & Yes & No \\
\hline 16 & Frequent AED prescribing changes & *Refer to patient notes & $\begin{array}{l}\text { Frequent changes of AED dosage compared with unchanged } \\
\text { dosage found to be a risk factor for SUDEP }(19,35)\end{array}$ & No & No & No \\
\hline
\end{tabular}

Figure 1 (A and B) Snapshots of sudden unexpected death in epilepsy and seizure safety checklist. The checklist is freely available in the UK. To access it, a request needs to be made by submitting an email. If the email is from a government department or university, no further information is required and the checklist is emailed to the requester. However, if a private email address is used (eg, john.smith@gmail.com), then a few details of who and why the checklist is being requested are asked for. There are two reasons for this: (A) The checklist risk factors are updated each year based on reviews of evidence and contact details ensure the update is emailed to all users. (B) The contact detail allows for audit and feedback processes on issues such as frequency of use, ease of use, barriers to implementation and so on. 
A

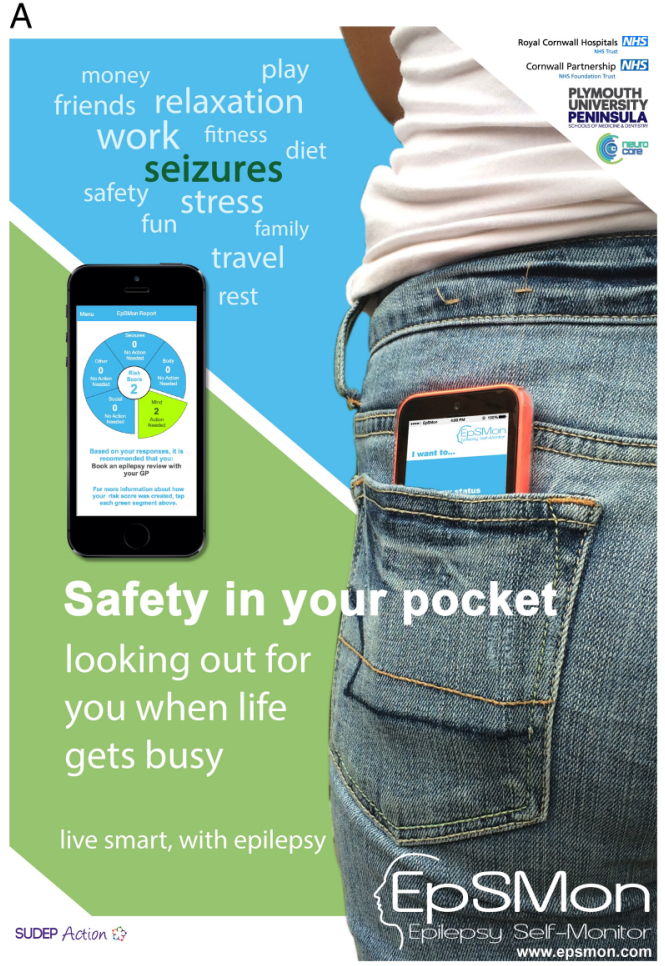

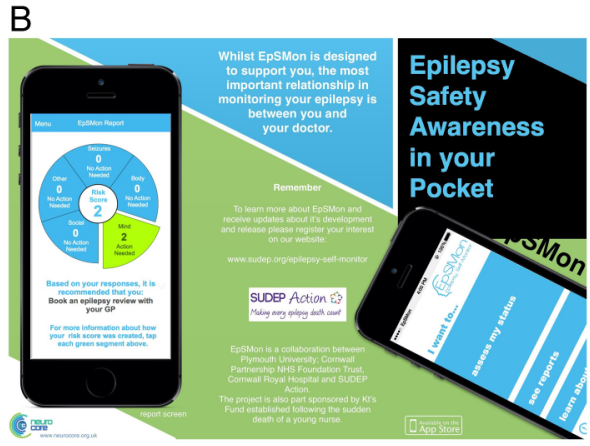

Figure 2 (A and B) Epilepsy self-monitor mobile phone app—poster and flier.

were clearly promising. ${ }^{26}$ Most available devices detect movement and/or physiological changes that occur before or during a seizure such as altered blood oxygen levels, heart rate changes, electrical activity in muscles and changes in galvanic skin resistance. Whether we can call seizure-alert dogs a 'device' is debatable.

\section{Movement sensors}

These comprise a pressure sensor map placed under the mattress or sheets to detect an abnormal movement and absence of movement. While weight and sleep movement adjustments can be made, seizure detection rates are variable, with the most successful devices picking up $89 \%$ of tonic-clonic seizures, ${ }^{27}$ although one study failed to detect any seizures. Specificity is poor, with frequent false positives, so disrupting sleep of both carers and patients. As with all sensor devices for epilepsy, they also raise issues of individual privacy. Nonetheless, these remain the most popular among parents because of their simplicity.

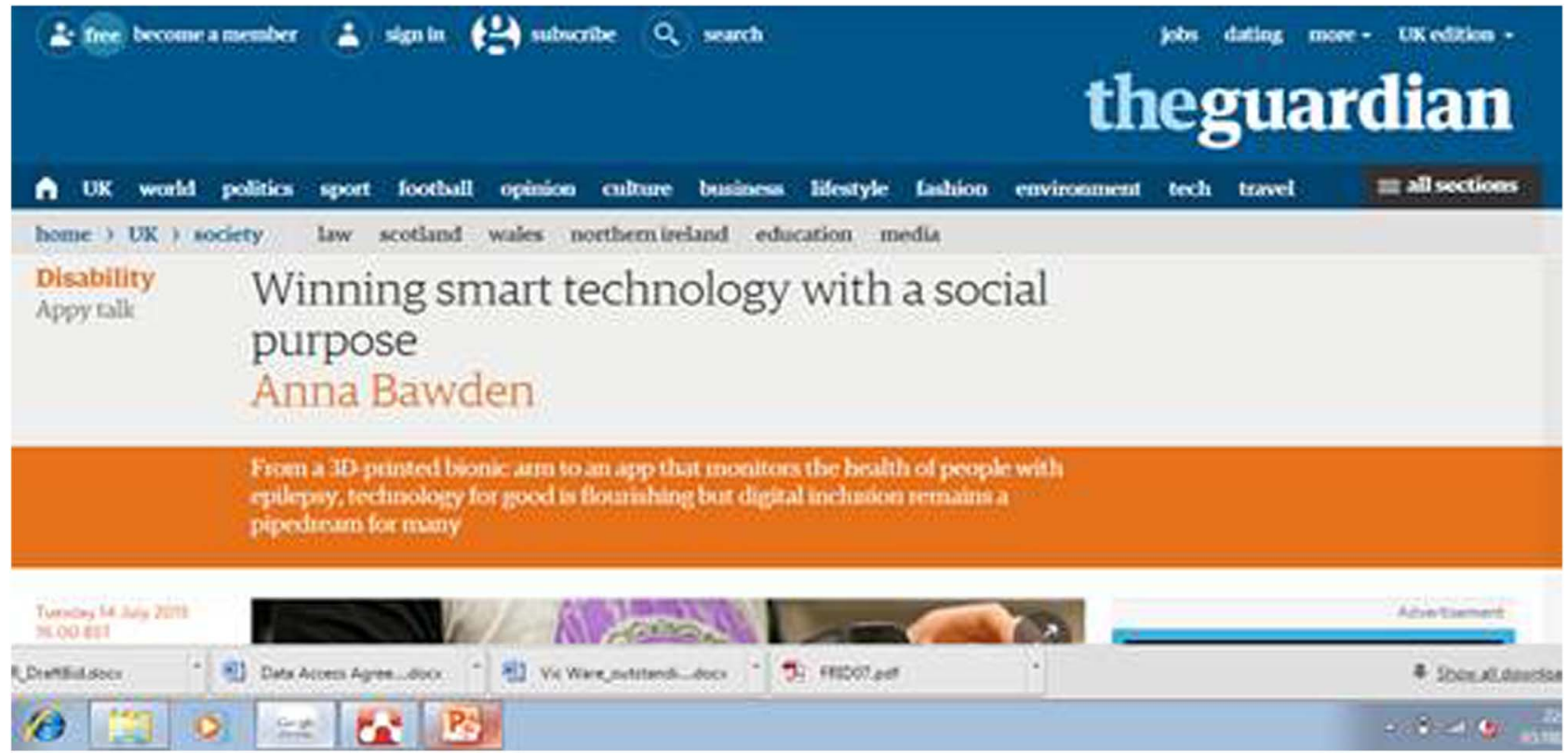

Figure 3 The Guardian newspaper review—highlighting the potential impact of technology. 
A

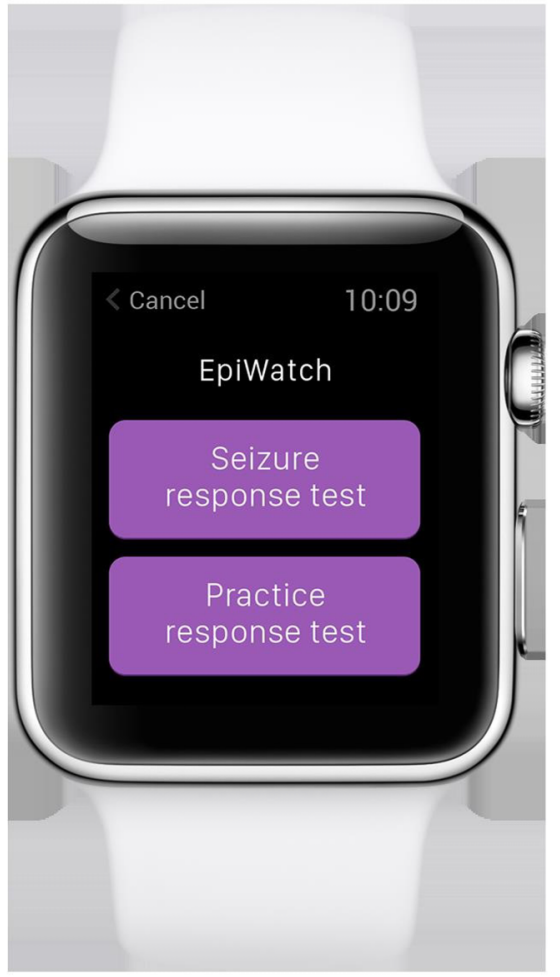

B

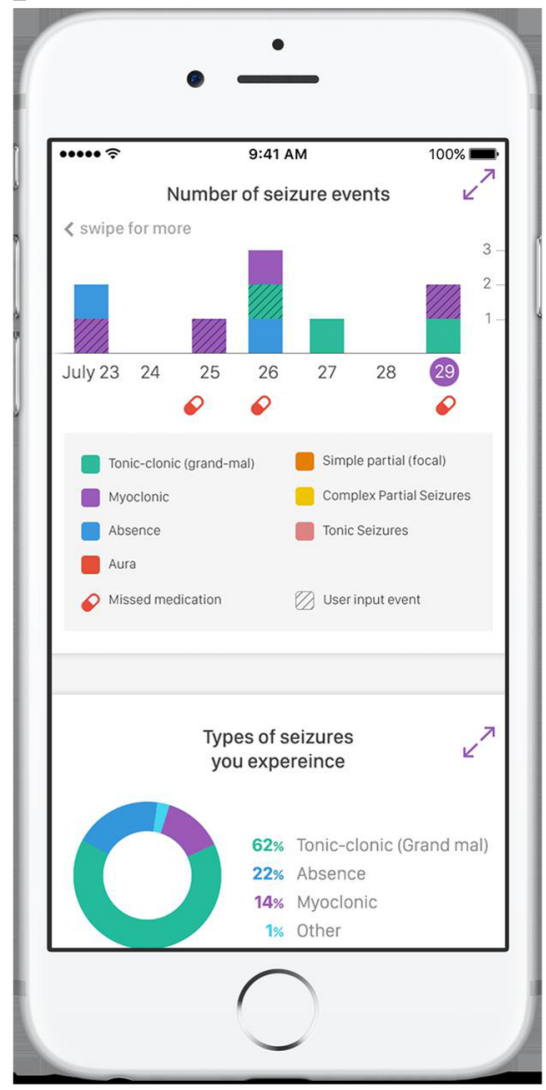

Figure 4 (A and B) Epiwatch—iWatch and iPhone link.

\section{Accelerometers}

These detect motion and change in velocity in two or three dimensions. Smartphones are particularly good for this. Sensitivity can be as high as $95 \%,{ }^{28}$ but again specificity is lower. Speed of detection in one study was a median of $17 \mathrm{~s}$ with all detected within $30 \mathrm{~s}^{29}$

The use of two accelerometers may improve nocturnal seizure detection.

\section{Physiological changes}

Seizure onset is associated with altered autonomic activity, including decreased skin resistance. When combined with an accelerometer, a galvanic device detected $94 \%$ of seizures, but with a significant false positive rate. ${ }^{30}$

Heart rate monitors in one study were $100 \%$ sensitive for tonic-clonic convulsions, and almost good for myoclonic seizures, but attempts to refine by adding breathing detectors or electromyographic analysis provided no advantage.

Apnoea devices combined with heart rate monitors are attractive in theory, but studies have not yet shown any benefits.

\section{Electromyography}

There are no devices for home use, but when combined with video electroencephalogram (EEG), there was $100 \%$ sensitivity within $30 \mathrm{~s}$ for tonic-clonic convulsions. Thus, the assessment of a more suitable device is in progress.

\section{Video and infrared devices}

Video monitoring is feasible, but has not been validated by EEG support. Infrared movement monitors reliably correlate with carer-reported activity, which did not necessarily confirm seizures. ${ }^{31}$ Using infrared spectroscopy to measure blood oxygen changes failed to detect seizures.

\section{Seizure-alert dogs}

There are numerous anecdotal reports of dogs successfully detecting seizures, but no rigorous studies. ${ }^{32}$ Dogs may alert to the seizure itself but not to its onset. Dogs may also react both to non-epileptic seizures and epileptic seizures, and so are not specific. One study reported seizure reduction but our group experienced the tragedy of a patient being killed by her dog that was responding to a seizure.

\section{Antisuffocation pillows}

These are often purchased by families, and are advertised on epilepsy support websites, with one study on carbon dioxide retention properties showing theoretical benefits. ${ }^{33}$ There is also the advantage that they are cheap and harmless. 


\section{FUTURE DEVELOPMENTS}

Refinements in safety checklists to provide semiquantified risk stratification may become more powerful in anticipating the risks of SUDEP. ${ }^{22}$ The future will be in using readily available technologies with which patients are already familiar. Self-monitoring will increasingly use innovations in powerful devices such as smartphones and smartwatches. 'Embrace', a smartphone self-monitoring app based on physiological measurements (physiological stress, arousal, sleep and physical activity), is now marketed in the USA. It has a built-in accelerometer, gyroscope, electrodermal activity sensor and peripheral temperature sensor and provides a personalised insight to an individual's activity and seizures. It links to a smartphone and claims to detect convulsive seizures alerting others via a smartphone link. However, there are no available trial data to support its claims. A miniature apnoea detection device and respiratory monitor showed 100\% sensitivity and specificity in detecting apnoeas, with a clinical trial now planned. 'Epiwatch', an app for the new iWatch developed by researchers at Johns Hopkins Hospital in Baltimore, Maryland, USA, offers a seizure recording and medication monitoring facility and has the potential to be linked to seizure detection devices (figure $4 \mathrm{~A}, \mathrm{~B}$ ).

\section{SUMMARY}

People with epilepsy need a person-centred, shared-care approach, including early discussion of SUDEP. Achieving seizure freedom through a careful choice of medication and consideration of surgical interventions is all important. Only long-term studies will determine whether safety checklists, telehealth interventions and mobile technologies have an impact. We have used these approaches for several years, and have seen SUDEP in our region fall in the intellectually disabled community from 4-5/year to nil, and in the non-intellectually disabled community from 6 to $1-2 /$ year. How much of this is from the checklist, and how much from increased awareness among clinicians, the media and people with epilepsy or from improved services in general is difficult to determine. However, these interventions do raise the profile of epilepsy mortality and may contribute to enhanced awareness. Device technology is still in its infancy, and we cannot recommend any single device particularly as none has been shown to prevent SUDEP. The ideal drug-one that suppresses all seizure activity and is free from side effects-may not be developed in our lifetime. Furthermore, clinically based interventions will not capture those individuals at high risk. Self-monitoring by people with epilepsy or carers remains important, although there will still be those whose lifestyles put them at risk. Good communication is essential, but current services are not structured with that in mind. Professionals can only do so much, leaving a service gap between the epilepsy professionals, who see a snapshot of a patient's life, and the day-to-day experiences of people with epilepsy. Empowering people with epilepsy to take responsibility for their condition would do much to bridge that gap.

\section{Key points}

- Sudden unexpected death in epilepsy (SUDEP) should be discussed at an early stage.

- Seizure freedom is the most important factor in preventing SUDEP; choice of medication, perseverance with medication changes and consideration of surgeries are the best ways to achieve this.

- Safety checklists, telehealth interventions and mobile technologies, such as epilepsy self-monitor, may reduce the chance of SUDEP.

- Device technologies for seizure detection have so far been disappointing.

- Patient empowerment is essential if we are to prevent SUDEP.

Contributors BM wrote the first draft of the article, with additional input, references and corrections by the coauthors who also provided some of the figures.

Competing interests Epilepsy self-monitor (EpSMon) has been a joint development between SUDEP Action, Plymouth

University, Cornwall Partnership NHS Foundation Trust and The Royal Cornwall Hospitals NHS Trust, to which the authors are affiliated. The SUDEP and Seizure Safety Checklist is a development of the Cornwall Partnership NHS Foundation Trust. EpSMon is provided as a free service in the UK. Any proceeds from the US version will be shared between the developing organisations in the UK and the USA.

Provenance and peer review Commissioned; externally peer reviewed. This paper was reviewed by Sam Lhatoo, Cleveland, Ohio, USA.

\section{REFERENCES}

1 Hanna NJ, Black M, Sander JW, et al. The National Sentinal Audit of Epilepsy-Related Death: epilepsy-death in the shadows. The Stationary Office, 2002.

2 Thurman DJ, Hesdorffer DC, French JA. Sudden unexpected death in epilepsy: assessing the public health burden. Epilepsia 2014;55:1479-85.

3 Wheller L, Baker A, Griffiths C, et al. Trends in avoidable mortality in England and Wales, 1993-2005. Health Stat Q 2007;34:6-25.

4 Office for National Statistics. Death registrations summary table, England and Wales. UK: Office for National Statistics, 2013.

5 Ridsdale L. Avoiding premature death in epilepsy. BMJ 2015;350:h718.

6 Fazel S, Wolf A, Långström N, et al. Premature mortality in epilepsy and the role of psychiatric comorbidity: a total population study. Lancet 2013;382:1646-54.

7 Shankar R, Cox D, Jalihal V, et al. Sudden unexpected death in epilepsy (SUDEP): development of a safety checklist. Seizure 2013;22:812-7.

8 The Epilepsies: diagnosis and management. London, UK: NICE, 2004 (CG20). 
9 The Epilepsies: diagnosis and management. London, UK: NICE, 2012 (CG137).

10 Diagnosis and management of epilepsy in adults. Edinburgh: SIGN, 2015 (SIGN 143 May 2015).

11 Waddell B, McColl K, Turner C, et al. Are we discussing SUDEP? A retrospective case note analysis. JNNP 2012;83 (Suppl 2):A4.

12 Ryvlin P, Cucherat M, Rheims S. Risk of sudden unexpected death in epilepsy in patients given adjunctive antiepileptic treatment for refractory seizures: a meta-analysis of placebo-controlled randomised trials. Lancet Neurol 2011;10:961-8.

13 Shankar R, Newman C, Hanna J, et al. Keeping patients with epilepsy safe: a surmountable challenge? BMJ Qual Impr Rep 2015;4.

14 Loiseau P, Marchal C. Determinants of compliance in epileptic patients. Epilepsy Res Suppl 1988;1:135-40.

15 Crawford P. Best practice guidelines for the management of women with epilepsy. Epilepsia 2005;46(Suppl 9):117-24.

16 Luciano AL, Shorvon SD. Results of treatment changes in patients with apparently drug-resistant chronic epilepsy. Ann Neurol 2007;62:375-81.

17 Téllez-Zenteno JF, Dhar R, Wiebe S. Long-term seizure outcomes following epilepsy surgery: a systematic review and meta-analysis. Brain 2005;128(Pt 5):1188-98.

18 Boon P, Vonck K, van Rijckevorsel K, et al. A prospective, multicenter study of cardiac-based seizure detection to activate vagus nerve stimulation. Seizure 2015;32:52-61.

19 Beran RG. SUDEP revisited-a decade on: have circumstances changed? Seizure 2015;27:47-50.

20 World Alliance for Patient Safety. WHO guidelines for safe surgery. Geneva: World health Organisation, 2008.

21 Brown S, Shankar R, Cox D, et al. Clinical governance: risk assessment in SUDEP. Clin Gov Int J 2013;18:325-31.

22 Shankar R, Walker M, Mclean B, et al. Steps to prevent SUDEP: the validity of risk factors in the SUDEP and seizure safety checklist: a case control study. J Neurol 2016;263:1840-6.
23 Shankar R, Newman C, Mclean B, et al. Can technology help reduce risk of harm in patients with epilepsy? Br J Gen Practice 2015;65:448-9.

24 Shankar R, Jalihal V, Walker M, et al. A community study in Cornwall UK of sudden unexpected death in epilepsy (SUDEP) in a 9-year population sample. Seizure 2014;23: 382-5.

25 Newman C, Shankar R, Hanna J, et al. Developing an evidence-based epilepsy risk assessment ehealth solution: from concept to market. JMIR Res Protoc 2016;5:e82.

26 Jory C, Shankar R, Coker D, et al. Safe and sound? A systematic literature review of seizure detection methods for personal use. Seizure 2016;36:4-15.

27 Narechania A, Garić II, Sen-Gupta I, et al. Assessment of a quasi-piezoelectric mattress monitor as a detection system for generalized convulsions. Epilepsy Behav 2013;28:172-6.

28 Cuppens $\mathrm{K}$, Chen $\mathrm{CW}$, Wong $\mathrm{KB}$, et al. Using station temporal interest points (STIP) for myoclonic jerk detection in nocturnal video. Conf Proc IEEE Eng Med Biol Soc 2012;2012:4454-7.

29 Kramer U, Kipervasser S, Shlitner A, et al. A novel portable seizure detection alarm system: preliminary results. J Clin Neurophys 2011;28:36-8.

30 Poh MZ, Loddenkemper T, Swenson NC, et al. Continuous monitoring of electrodermal activity during epileptic seizures using a wearable sensor. Conf Proc IEEE Eng Med Biol Soc 2010;2010:4415-8.

31 Shankar R, Jory C, Tripp M, et al. Monitoring nocturnal seizure in vulnerable patients. Learn Dis Pract 2013;16:36-8.

32 Brown SW, Goldstein LH. Can seizure-alert dogs predict seizures? Epilepsy Res 2011;97:236-42.

33 Catcheside PG, Mohtar AA, Reynolds KJ. Airflow resistance and $\mathrm{CO} 2$ rebreathing properties of anti-asphyxia pillows designed for epilepsy. Seizure 2014;23:462-7. 